\title{
Analysis Of Stock Control Of Raw Materials Of Dzohir Noodles In Bengkulu
}

\section{Analisis Pengendalian Persediaan Bahan Baku Mie Dzohir Di Bengkulu}

\author{
Monika Ahmelia1); Herlin²); Abdul Rahman ${ }^{3)}$ \\ Department of Accounting, Faculty of Economic, Universitas Dehasen Bengkulu \\ Email: ${ }^{1)}$ monikaahmelia09@gmail.com
}

\begin{abstract}
How to Cite:
Ahmelia, M., Herlin, H., Rahman, A. (2021). Analysis Of Stock Control Of Raw Materials Of Dzohir Noodles In Bengkulu. JURNAL EMAK: Jurnal Ekonomi Manajemen Akuntansi Dan Keuangan, 3(1). DOI: https://doi.org/10.53697/emak.v3i1
\end{abstract}

ARTICLE HISTORY
Received [18 Desember 2021]
Revised [28 Desember 2021]
Accepted [1 Januari 2021]
KEYWORDS
Feasibility Study, Marketing
Aspect, Financial Aspect,
Culinary Business

This is an open access article under the CC-BY-SA license

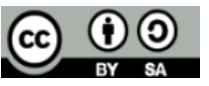

\section{ABSTRAK}

Penelitian ini bertujuan untuk menganalisis pengendalian persediaan bahan baku Mie Dzohir di Bengkulu. Metode analisis yang digunakan adalah Economic Order Quantity (EOQ), Reorder Point (ROP), Total Inventory Cost (TIC) dan Safety Stock (SS).

Hasil penelitian menunjukkan bahwa untuk memenuhi kebutuhan bahan baku sebesar 91.375 kg selama periode penelitian, dari Januari sampai Desember (12 bulan), maka total pembelian yang hemat/EOQ bahan baku tepung terigu yang harus dilakukan oleh pabrik Mie Dzohir di Bengkulu adalah sebanyak 5.372 kg setiap kali pemesanan dengan frekuensi pembelian sebanyak 17 kali selama satu periode dari Januari 2020 sampai dengan Desember 2020. Pemesanan kembali atau reorder point (ROP) juga dapat ditentukan yaitu pemesanan kembali seharusnya dilakukan pada saat persediaan digudang sebanyak $345 \mathrm{~kg}$, dengan lead time 1 hari agar tidak menghambat proses produksi perusahaan. Total inventory cost (TIC) juga dapat ditentukan yaitu total biaya persediaan bahan baku sebesar Rp. 3.572.188,- sehingga dapat menghemat biaya persediaan sebesar Rp. 1.051.697,- .Safety stock (SS) sebesar $95 \mathrm{~kg}$ yang harus ada digudang, hal ini dimaksudkan agar tidak terjadi kekurangan bahan baku tepung terigu apabila terjadi keterlambatan pengiriman bahan baku.

\section{ABSTRACT}

This study aims to analyze the stock inventory control of Mie Dzohir's raw materials in Bengkulu. The analytical method used is Economic Order Quantity (EOQ), Reorder Point (ROP), Total Inventory Cost (TIC) and Safety Stock (SS). The results showed that to meet the raw material needs of 91,375 kg during the research period, from January 2020 to December 2020 (12 months), the number of economical purchases/EOQ of wheat flour raw materials that had to be made by the Mie Dzohir factory in Bengkulu was as much as 5,372 kg for each order with a purchase frequency of 17 times for a period from January 2020 to December 2020. Reorders or reorder points (ROP) can also be determined, namely reordering should be done when $345 \mathrm{~kg}$ of inventory is in warehouse, with a lead time of 1 days so as not to hamper the company's production process. The total inventory cost (TIC) can also be determined, namely the total cost of raw material inventory of Rp. 3.572.188, - therefore, it can save on inventory costs of Rp. 1.051.697,.Safety stock (SS) of $95 \mathrm{~kg}$ which must be in the warehouse, this is intended therefore, there is no shortage of wheat flour raw materials if there is a delay in the delivery of raw materials. 


\section{PENDAHULUAN}

Perkembangan Indonesia era ini bertambah pesat, karena setiap perusahaan kini mulai bersaing dengan ketat sehingga perusahaan berlomba-lomba mebuat suatu produk agar kualitas dan kuantitas yang diharapkan dengan biaya seminimal mungkin, maka dari itu pentingnya metode yang benar agar menciptakan suatu barang yang nantinya dapat diterima para konsumen. Adanya persediaan bahan baku maka hendaknya perusahaan manufaktur menjalankan langkah-langkah produksi kebutuhan konsumen yang sesuai, menetapkan pengendalian persediaan yang memadai agar aktivitas produksi pada pelanggan perusahaan tidak kekurangan bahan baku dimasa depan. Ada banyak metode penanganan bahan baku yang dipakai. Penelitian ini menggunakan metode EOQ, Reorder Point (ROP), Total Inventary Cost (TIC) dan Safety Stock (SS). Menurut Heizer dan Render, (2015 : 561) EOQ yaitu cara pengendalian yang mudah dengan konsepsi pengendalian terbilang bisa untuk menemukan total (Q) tiap pesanan sehingga TIC menjadi minimum. Mie Dzohir di Bengkulu merupakan bisnis mie milik pribadi yang memproduksi berbagai macam mie salah satunya mie kwetiau. Banyaknya bisnis yang serupa tidak menyebabkan Mie Dzohir menyerah, justru sampai kini mie buatan persusahaan Mie Dzohir di Bengkulu terus-menerus dibeli habis oleh konsumennya. Bahan baku yang digunakan langkah-langkah dalam membuat Mie Dzohir yaitu tepung terigu dan dalam pengoperasian proses produksi bahan baku maka diharuskan tersedianya bahan baku setiap saat agar proses produksi berjalan dengan lancar, akan tetapi tepung terigu yang disimpan dalam jangka waktu yang lama dan terjadi penumpukan di gudang maka akan mengalami keusangan dan kerusakan. Maka dari itu peneliti menetapkan tempat penelitian di pabrik Mie Dzohir agar pemilik usaha ini memahami pentingnya metode EOQ, ROP, TIC DAN SS dalam persediaan bahan baku.

\section{TINJAUAN PUSTAKA}

\section{Persediaan Barang}

Persediaan yaitu kinerja perusahaan untuk menjalankan setiap permintaan barang mentah, setengah jadi maupun barang jadi agar terus tersedia bagus dallam situasi pasar yang berfluktuasi atau stabil.

\section{Pengertian Bahan Baku}

Bahan baku yaitu salah satu bahan yang terpenting didalam perusahaan manufaktur, karena bahan baku proses pertama dalam produksinya. Ketika perusahaan menemukan bahan baku input berupa barang setengah jadi, hingga perusahaan dapat membuat bahan baku input menjadi barang output.

\section{Pengendalian Persediaan Bahan Baku}

Pengendalian persediaan merupakan tindakan dalam menaksirkan total persediaan yang benar, dengan total yang tidak sedikit maupun besar dibandingkan permintaan.

\section{Economic Order Quantity}

Perusahaan memerlukan metode EOQ untuk menemukan kuantitas pemesanan yang terbaik. Dalam metode ini perusahaan dapat menentukan jumlah pembelian yang hemat dengan menetapkan kebutuhan dalam satu periode yang ditentukan, biaya pemesanan dan penyimpanan.

\section{Reorder Point}

Perhitungan Reorder Point setiap kali pembelian memperhitungkan total persediaan yang ada di gudang, maka pada saat total persediaan tertentu perusahaan harus melakukan pemesanan dan menentukan kapan pemesanan kembali yang harus dilakukan. Hal ini dilakukan agar persediaan perusahaan tidak kekurangan bahan baku jika nanti terjadinya keterlambatan proses pengiriman. 
TIC

Untuk dapat menentukan total biaya atau TIC yang minimum maka harus membandingkan antara perhitungan biaya persediaan yang dilakukan suatu perusahaan dan menurut perhitungan dengan menggunakan metode EOQ.

SS

Perusahaan harus selalu menyediakan stok pengaman agar bahan baku tidak kehabisan stok jika dimasa depan terjadinya keterlambatan pengiriman atau terjadinya kerusakan yang dapat menyebabkan terhentinya proses produksi.

\section{Metode Analisis}

\section{METODE PENELITIAN}

Metode analisis yang digunakan dalam penelitian ini yaitu :

a. Analisis Economic Order Quantity (EOQ)

Untuk dapat menentukan jumlah kuantitas pemesanaan yang optimal dan meminimalisirkan biaya yang dikeluarkan oleh pabrik Mie Dzohir di Bengkulu. Adapun di dalam menetapkan metode Economic Order Quantity (EOQ) dapat dihitung dengan suatu persamaan atau rumus. Heizer dan Render (2015: 563), penghitungan Economic Order Quantity (EOQ) dapat menggunakan rumus sebagai berikut:

$\mathrm{EOQ}=$

Dimana :

EOQ = Jumlah pembelian optimal yang ekonomis

$\mathrm{D} \quad \quad=$ permintaan yang diperkirakan per periode waktu

$\mathrm{S} \quad=$ Biaya pemesanan per pesanan

$\mathrm{H} \quad$ = Biaya penyimpanan perunit per tahun

b. Analisis Reorder Point (ROP)

Kapan pemesanan kembali sehingga biaya optimal dapat dilakukan, yaitu pada saat titik dimana perusahaan mempunyai batas barang yang harus ada untuk dapat memenuhi pesanan konsumen, dengan memperhatikan lead time. Rumus untuk menentukan titik pemesanan ulang (Reorder Point) menurut Heizer dan Render (2015: 567) sebagai berikut:

$\mathrm{ROP}=\mathrm{D} \times \mathrm{L}$

Dimana :

D = permintaan per hari

$\mathrm{L} \quad \quad=$ waktu tunggu pesanan (dalam hari)

Rumus ROP akan berubah apabila disertakan persediaan pengamanan. Berikut adalah rumus ROP dengan persediaan pengamnan :

$\mathrm{ROP}=(\mathrm{D} \times \mathrm{L})+\mathrm{SS}$

Dimana :

D = Kebutuhan rata-rata bahan baku perhari

L $\quad=$ Lead Time

A $\quad=$ Safety Stock

c. Total Inventory Cost (TIC)

Untuk memperoleh total biaya persediaan bahan baku dengan menggunakan rumus Heizer dan Render (2015: 563) sebagai berikut:

$\mathrm{TIC}=[\mathrm{D} / \mathrm{Q} . \mathrm{S}]+[\mathrm{Q} / 2 . \mathrm{H}]$

Dimana :

$\mathrm{Q} \quad=$ Jumlah optimal tepung terigu perpesan

34 | Monika Ahmelia; Herlin; Abdul Rahman; Analysis Of Stock Control... 
$\mathrm{H}$

$\mathrm{S}$
= Biaya penyimpanan per tahun

= Biaya pemesan sekali pesan

d. Safety Stock (SS)

Metode safety stock digunakan untuk mengetahui tingkat pengaman persediaan. Sebelum menentukan Safety Stock, terlebih dahulu harus mengetahui nilai standar deviasinya yaitu dengan rumus Heizer dan Render (2015:567) sebagai berikut :

$\mathrm{SD}=\sqrt{ }\left(\left(\sum\left(X-1-X^{-}\right)^{\wedge} 2 \dashv\right) / \mathrm{N}\right)$

Dimana :

$\mathrm{SD} \quad=$ Standar deviasi

$X \quad=$ Perkiraan pemakaian

$\mathrm{X}^{-} \quad=$ Pemakaian sesungguhnya

$\mathrm{N} \quad=$ Jumlah data

Setelah nilai standar deviasi diketahui, maka selanjutnya menghitung safety stock dengan rumus Heizer dan Render (2015:567) sebagai berikut:

$\mathrm{SS}=\mathrm{Z} \times \mathrm{SD}$

Dimana :

SS = Safety Stock

$\mathrm{Z} \quad=$ Nilai $\mathrm{a}$ dengan penyimpangan $5 \%$ yang dilihat pada tabel $\mathrm{Z}$.

$\mathrm{SD} \quad=$ Standar Deviasi

\section{HASIL DAN PEMBAHASAN}

a. Economic Order Quantity (EOQ)

pembelian bahan baku yang ekonomis ini didasarkan pada:

Dimana :

D = Total kebutuhan bahan baku (91.375)

$\mathrm{S} \quad=$ Biaya pemesanan per pesanan (Rp. 105.000)

$\mathrm{H} \quad$ = Biaya penyimpanan perunit per tahun

Maka besarnya pembelian bahan baku yang ekonomis menggunakan metode EOQ adalah sebagai berikut :

$$
\begin{aligned}
& \mathrm{EOQ}=\sqrt{\frac{2 S D}{H}} \\
& \mathrm{EOQ}=\sqrt{\frac{2 \times 105.000 \times 91.375}{665}} \\
& \mathrm{EOQ}=\sqrt{\frac{19.188 .750 .000}{665}} \\
& \mathrm{EOQ}=\sqrt{28.855 .263} \\
& \mathrm{EOQ}=5.371,70 \mathrm{~kg} \text { pembulatan menjadi } 5.372 \mathrm{~kg}
\end{aligned}
$$

b. Frekuensi pemesanan bahan baku tepung terigu

Dengan menggunakan metode EOQ dapat dihitung jumlah frekuensi pemesanan dalam satu tahun atau sering disebut frekuensi, dapat dihitung sebagai berikut:

$$
\begin{aligned}
\mathrm{I} & =\frac{\mathrm{R}}{\mathrm{EOQ}} \\
\mathrm{I} & =\frac{91.375}{5.372} \\
& =17,00 \text { atau dibulatkan menjadi } 17 \text { kali pembelian }
\end{aligned}
$$


c. Analisis Total Inventory Cost (TIC)

Agar dapat menghitung biaya persediaan yang diperlukan,maka diketahui :

$\mathrm{D} \quad=$ Total kebutuhan bahan baku (91.375)

$\mathrm{S} \quad=$ Biaya pemesanan per pesanan (Rp. 105.000)

$\mathrm{H} \quad$ = Biaya penyimpanan perunit per tahun (Rp. 665)

$\mathrm{Q} \quad=$ Pembelian rata-rata bahan baku ekonomis (4.014 kg)

Total Inventory Cost (TIC) sebagai berikut :

$$
\begin{aligned}
\mathrm{TIC} & =\left[\frac{D}{Q} \cdot S\right]+\left[\frac{Q}{2} \cdot H\right] \\
\mathrm{TIC} & =\left[\frac{91.375}{5.372} \cdot 105 \cdot 000\right]+\left[\frac{5.372}{2} \cdot 665\right] \\
\mathrm{TIC} & =(17 \times 105 \cdot 000)+(2.687,5 \times 665) \\
\mathrm{TIC} & =1.785 .000+1.787 .187,5 \\
\mathrm{TIC} & =\text { Rp. 3.572.188 }
\end{aligned}
$$

\section{d. Analisi Safety Stock}

Persediaan pengaman ini sering juga disebut dengan istilah Safety Stock, di dalam suatu perusahaan yang besar Safety Stock ini sangat diperlukan, guna menunjang kelancaran produksi yang berlangsung seperti hanya menghindari kekurangan bahan baku yang akan mengakibatkan keryawan tidak bekerja. Dalam memperhitungkan persediaan pengaman digunakan metode statistik dengan membandingkan rata-rata bahan baku dengan pemakaian bahan baku yang sesungguhnya, kemudian dicari penyimpangan. Untuk mencari penyimpangan tersebut digunakan perhitungan standar deviasi.

$$
\begin{aligned}
& \mathrm{SD}=\sqrt{\frac{\sum(\mathrm{x}-\overline{\mathrm{X}})^{2}}{\mathrm{~N}}} \\
& \mathrm{SD}=\sqrt{\frac{119.359}{36}} \\
& \mathrm{SD}=\sqrt{3.315,5} \\
& \mathrm{SD}=57,58
\end{aligned}
$$

Dengan menggunakan perkiraan atau asumsi bahwa perusahaan memenuhikebutuhan bahan baku sebanyak 95\% dan persediaan cadangan 5\% maka diperoleh nilai Safety factor sebesar 1,645 (tabel terlampir).

$$
\begin{aligned}
\text { Safety Stock } & =\mathrm{Z} \times \mathrm{SD} \\
& =1,645 \times 57,58 \\
& =94,71 \\
\text { pembulatan } & =95 \mathrm{~kg}
\end{aligned}
$$

persediaan pengaman (Safety Stock)yang harus disediakan adalah sebanyak $95 \mathrm{~kg}$ yang tetap dipertahankan di gudang guna mengantisipasi kekurangan bahan baku dan dapat digunakan apabila keterlambatan pesanan sehingga dalam proses produksi dapat terus berjalan.

e. Analisis Reoder Point (ROP)

a. Lead Time (Waktu Tunggu)

waktu tunggu atau Lead Time yang ditetapkan perusahaan adalah sahari sebelum bahan baku habis atau H-1. Sehari sebelum bahan baku tepung terigu habis Mie Dzohir di Bengkulu segera melakukan pemesanan kembali untuk menghindari resiko keterlambatan.

36 | Monika Ahmelia; Herlin; Abdul Rahman; Analysis Of Stock Control... 
b. Analisis Reorder Point (ROP)

Setelah diketahui jumlah pembelian Ekonomis (EOQ), waktu tunggu dan safety stock, maka titik reoder point dapat ditentukan. Dan dengan rata-rata jumlah kerja karyawan selama 365 hari dalam setahun.

Sebelum menghitung ROP, maka terlebih dahulu dicari tingkat penggunaan bahan baku perhari dengan cara sebagai berikut :

$$
\begin{aligned}
& d=\frac{D}{t} \\
& d=\frac{91.375}{365} \\
& d=250,34 \\
& \text { Maka Reoder Point (ROP) adalah sebagai berikut : } \\
& \text { ROP }=(D \times L)+S S \\
& \text { ROP }=(250,34 \times 1)+95 \\
& \text { ROP }=345,34 \text { pembulatan menjadi }=345 \mathrm{~kg}
\end{aligned}
$$

f. Hasil Perhitungan Biaya Persediaan Bahan Baku Mie Dzohir Di Bengkulu Periode Januari 2020 Desember 2020

Dari hasil perhitungan yang telah dilakukan, maka dapat dilihat biaya persediaan bahan baku Mie Dzohir di Bengkulu dari bulan januari 2020 sampai dengan desember 2020 adalah sebagai berikut :

Tabel 1. Hasil Perhitungan Biaya Persediaan Bahan Baku Mie Dzohir Di Bengkulu Periode Januari 2020 - Desember 2020

\begin{tabular}{|c|l|l|}
\hline No. & \multicolumn{1}{|c|}{ Keterangan } & \multicolumn{1}{c|}{ Jumlah } \\
\hline 1. & EOQ & $5.372 \mathrm{~kg}$ \\
\hline 2. & Frekuensi pembelian/tahun & $17 \mathrm{kali}$ \\
\hline 3. & TIC & Rp. 3.572 .188 \\
\hline 4. & $S S$ & $95 \mathrm{~kg}$ \\
\hline 5. & ROP & $345 \mathrm{~kg}$ \\
\hline
\end{tabular}

Sumber : Hasil penelitian, 2021

\section{Pembahasan}

Dari hasil perhitungan yang telah dilakukan, maka dapat dilihat perbandingan bahan baku antara Mie Dzohir di Bengkulu dengan pendekatan menggunakan metode EOQ, ROP, TIC dan SS sebagai berikt :

Terlihat rata-rata kuantitas pembelian bahan baku berdasarkan Mie Dzohir di Bengkulu sebesar $2.538 \mathrm{~kg}$ sedangkan apabila menggunakan metode EOQ rata-rata kuantitas pembelian bahan baku adalah sebesar $5.372 \mathrm{~kg}$ kg per sekali pesan dengan kebutuhan bahan baku sama-sama sebesar $91.375 \mathrm{~kg}$ dari bulan Januari 2020 sampai dengan Desember 2020 (12 bulan). Total biaya persediaan yang dikeluarkan berdasarkan Mie Dzohir di Bengkulu sebesar Rp. 4.623.885,-, apabila menggunakan metode EOQ dan TIC total biaya persediaan bahan baku sebesar Rp. 3.572.188,- sehingga dapat menghemat biaya persediaan sebesar Rp.1.051.697,--

Selain itu dapat kita ketahui juga kebijakan pengendalian persediaan yang dilakukan oleh Mie Dzohir di Bengkulu masih kurang efektif dan efesien. Faktor yang menyebabkan kebijakan pengendalian persediaan perusahaaan kurang efektif dan efesien adalah dari biaya persediaan yang timbul karena adanya pemesanan dan penyimpanan, dan juga dari faktor frekuensi pemesanan bahan baku yang dilakukan perusahaan.

Dengan demikian membuktikan bahwa kebijakan pengendalian persediaan yang dilakukan Mie Dzohir di Bengkulu belum maksimal. Itu dibuktikan dari perhitungan jumlah total biaya persediaan antara kebijakan perusahaan dengan metode EOQ, ROP, TIC dan SS yang memiliki selisih sebesar Rp. 1.051.697,-. Dimana biaya persediaan sebesar Rp. 4.623.885,- menurut Mie Dzohir di 
Bengkulu lebih besar dibandingkan dengan perhitungan metode EOQ dan TIC sebesar Rp. 3.572.188,. Dan juga dapat mengetahui hasil Safety Stock (SS) yang harus ada di gudang sebanyak $95 \mathrm{~kg}$ dan Reorder Point (ROP) seharusnya dilakukan pada saat persediaan di gudang sebanyak $345 \mathrm{~kg}$. Oleh sebab itu, perusahaan perlu melakukan pengendalian persediaan untuk mencegah terjadinya kelebihan atau kekurangan persediaan yang akan mempengaruhi biaya persediaan. Penggunaan metode EOQ dan TIC pada Mie Dzohir di Bengkulu merupakan hal yang penting bagi perusahaan, karena kebijakan persediaan bahan baku yang dijalankan perusahaan selama ini tidak bisa memperkecil biaya, jadi dengan penerapan metode EOQ dan TIC akan memperkecil biaya. Pertimbangan jumlah pemesanan terhadap bahan baku akan memperkecil total biaya persediaan yang dikeluarkan kerena menurut perusahaan pemesanan dilakukan 36 kali sedangkan menurut perhitungan EOQ hanya 17 kali pembelian. Hasil penelitan peneliti menggunakan teori Heizer dan Rander (2015:563-567).

Hasil penelitian ini didukung oleh penelitian sebelumnya yaitu Sari (2019) yang menyatakan bahwa dengan menerapkan metode EOQ maka perusahaan mampu menentukan berapa persediaan bahan baku yang harus disediakan, berapa stock minimal bahan baku, berapa banyak bahan baku yang harus ada digudang agar proses produksi tidak terhenti. Hal lain yang dapat ditentukan dengan metode ini adalah Roeder Point yaitu titik dimana perusahaan harus memesan bahan baku dengan tujuan tidak terjadinya kekosongan bahan baku dan tidak menumpuknya bahan baku di gudang menggunakan teori Handoko (2016:340-348) dan Ahyari (2017:81-83).

Hasil penelitian ini juga didukung oleh penelitian Indah dan Risasti (2017) yang menyatakan bahwa penggunaan metode EOQ dalam hal pengendalian persediaan bahan baku lebih efektif dan efesien jika dibandingkan dengan kebijakan yang selama ini digunakan PT. Tri Agro Palma Tamiang.dalam hal ini dengan menerapkan metode EOQ perusahaan akan lebih menghemat biayabiaya yang berhubungan dengan persediaan, selain itu dengan menggunakan metode EOQ perusahaan akan terus berproduksi tanpa takut kehabisan bahan baku sehingga perusahaan bisa memenuhi permintaan konsumen setiap sat akan terhindar dari kerugian.

Sedangkan Sofiyanurriyanti (2017) menyatakan bahwa dengan menerapkan metode EOQ pada CV. Alfa Nafis didalam pembelian bahan baku baja ringan. Hal ini dapat dibuktikan dengan perhitungan EOQ perusahaan yang menyimpulkan bahwa pembelian bahan baku baja ringan yang ekonomis adalah 8.124 unit dengan frekuensi 4 kali pemesanan dalam satu tahun dengan menggunakan teori Handoko (2011:333) dan Heizer dan Render (2008: 75).

\section{KESIMPULAN DAN SARAN}

\section{Kesimpulan}

1. Untuk memenuhi kebutuhan bahan baku 1 periode ssebesar $91.375 \mathrm{~kg}$ selama periode penelitian yaitu dari bulan Januari 2020 sampai dengan Desember 2020 (12 bulan), maka jumlah pembelian yang ekonomis/EOQ bahan baku tepung terigu yang harus dilakukan oleh pabrik Mie Dzohir di Bengkulu adalah sebanyak $5.372 \mathrm{~kg}$ setiap kali pemesanan dengan frekuensi pembelian sebanyak 17 kali selama satu periode dari Januari 2020 sampai dengan Desember 2020.

2. Pemesanan kembali atau reorder point (ROP) juga dapat ditentukan yaitu pemesanan kembali seharusnya dilakukan pada saat persediaan digudang sebanyak $345 \mathrm{~kg}$, dengan lead time 1 hari agar tidak menghambat proses produksi perusahaan.

3. Total biaya persediaan atau total inventory cost (TIC) juga dapat ditentukan yaitu total biaya persediaan bahan baku sebesar Rp. 3.572.188,- sehingga dapat menghemat biaya persediaan sebesar Rp. 1.051.697,- dari total biaya persediaan yang dikeluarkan berdasarkan kebijakan perusahaan.

4. Persediaan pengaman/safety stock (SS) sebesar $95 \mathrm{~kg}$ yang harus ada digudang, hal ini dimaksudkan agar tidak terjadi kekurangan bahan baku tepung terigu apabila terjadi keterlambatan pengiriman bahan baku. 
Saran

1. Hendaknya perusahaan Mie Dzohir di Bengkulu meninjau kembali kebijakan yang dijalankan perusahaan mengenai pengendalian persediaan bahan baku.

2. Dalam menentukan persediaan bahan baku yang optimal dengan biaya yang minimum, frekuensi pemesanan yang minimal, waktu pemesanan kembali yang tepat waktu serta persediaan pengaman yang tepat agar tidak kekurangan bahan baku ataupun kelebihan baha baku. Maka perusahaan Mie Dzohir di Bengkulu sebaiknya mempertimbangkan untuk menggunakan metode EOQ, ROP, TIC dan SS.

\section{DAFTAR PUSTAKA}

Assauri. (2016). Manajemen Operasi Produksi. Jakarta: Edisi 3.

Damayanti. (2012). Tinjauan Pengendalian Bahan Baku Slab Pada Pt Hevea . Palembang: Politeknik Negeri Sriwijaya.

Fahmi, I. (2016). Pengantar Manajemen Keuangan. Bandung: Alfabeta.

Gunawan. (2013). Metode Penelitian Kualitatif Teori Dan Proktif. Jakarta: Bumi Aksara.

Heizer, J., \& Render, B. (2015). Manajemen Operasi. Jakarta: Salemba Empat.

Indah, D. R., \& Risasti, E. Y. (2017). Analisis Pengendalian Persediaan Bahan Baku Pada Pt.Tri Agro Palma Tamiang. Jurnal Samudra Ekonomi Dan Bisnis, Vol 8, No 2.

Kholmi, M. (2013). Akuntansi Biaya. Yogyakarta: Graha Ilmu.

Ristono, A. (2013). Manajemen Persediaan. Yogyakarta : Graha IImu.

Rudianto. (2012). Pengantar Akuntansi Konsep Dan Teknik Penyusunan Laporan Keuangan. Jakarta: Erlangga.

Sari, N. (2019). Pengendalian Persediaan Bahan Baku Dengan Menggunakan Metode Eoq Pada Usaha Krupuk Ikan Surya. Bengkulu: Universitas Dehasen Bengkulu.

Sjahrial, D. (2012). Pengantar Manajemen Keuangan. Jakarta: Mitra Wacana Media.

Sofiyanurrianti. (2017). Analisa Persediaan Bahan Baku Menggunakan Metode Eoq (Economic Order Quantity) Di Cv. Alfa Nafis. Jurnal IImiah Rekayasa, Vol 10 No 2.

Sugiyono. (2015). Penelitian Kuantitatif, Kualitatif, Dan R\&D. Bandung: Alfabeta.

Sujarweni. (2015). Akuntansi Biaya. Yogyakarta: Pustaka Baru Prss.

Sumayang, L. (2013). Dasar-Dasar Manajemen Produksi Dan Operasi. Jakarta: Salemba Empat.

Supriyono. (2013). Psikologi Belajar. Jakarta: Rineka Cipta.

Tampubulon, M. P. (2018). Manajemen Operasi Dan Rantai Pemasok. Jakarta: Mitra Wacana Media.

Wardani. (2014). Perencanaan Dan Pengendalian Persediaan Dengan Metode Eoq. Media Mahardika, Vol 13 No 3 